\title{
Benefiting From Misfortune: When Harmless Actions Are Judged to Be Morally Blameworthy
}

Yoel Inbar

David A. Pizarro

Fiery Cushman

Follow this and additional works at: https://repository.upenn.edu/fnce_papers

Part of the Finance and Financial Management Commons, and the Social and Behavioral Sciences Commons

\section{Recommended Citation}

Inbar, Y., Pizarro, D. A., \& Cushman, F. (2012). Benefiting From Misfortune: When Harmless Actions Are Judged to Be Morally Blameworthy. Personality and Social Psychology Bulletin, 38 (1), 52-62. http://dx.doi.org/10.1177/0146167211430232 


\title{
Benefiting From Misfortune: When Harmless Actions Are Judged to Be Morally Blameworthy
}

\author{
Abstract \\ Dominant theories of moral blame require an individual to have caused or intended harm. However, the \\ current four studies demonstrate cases where no harm is caused or intended, yet individuals are \\ nonetheless deemed worthy of blame. Specifically, individuals are judged to be blameworthy when they \\ engage in actions that enable them to benefit from another's misfortune (e.g., betting that a company's \\ stock will decline or that a natural disaster will occur). Evidence is presented suggesting that perceptions \\ of the actor's wicked desires are responsible for this phenomenon. It is argued that these results are \\ consistent with a growing literature demonstrating that moral judgments are often the product of \\ evaluations of character in addition to evaluations of acts.

\section{Disciplines} \\ Finance and Financial Management | Social and Behavioral Sciences
}




\section{Benefiting From Misfortune When Harmless Actions Are Judged to Be Morally Blameworthy}

Article in Personality and Social Psychology Bulletin · January 2012

DOI: $10.1177 / 0146167211430232 \cdot$ Source: PubMed

CITATIONS

50

3 authors, including:

\section{Yoel Inbar}

Tilburg University

25 PUBLICATIONS 993 CITATIONS

SEE PROFILE
READS

180
David A Pizarro

Cornell University

57 PUBLICATIONS 2,879 CITATIONS

SEE PROFILE

All content following this page was uploaded by Yoel Inbar on 23 August 2017. 


\title{
Benefiting from misfortune: \\ When harmless actions are judged to be morally blameworthy
}

\author{
Yoel Inbar, David Pizarro, Fiery Cushman
}

Dominant theories of moral blame require an individual to have caused or intended harm. However, across four studies we demonstrate cases where no harm is caused or intended, yet individuals are nonetheless deemed worthy of blame. Specifically, individuals are judged to be blameworthy when they engage in actions that enable them to benefit from another's misfortune (for example, betting that a company's stock will decline or that a natural disaster will occur). We present evidence suggesting that perceptions of the actor's wicked desires are responsible for this phenomenon. We argue that these results are consistent with a growing literature demonstrating that moral judgments are often the product of evaluations of character in addition to evaluations of acts.

The concept of blameworthy action is central both to the law (Hall, 1947) and to moral judgment (Weiner, 1995). A blameworthy action - a behavior that is "morally wrong or socially opprobrious" (Alicke, 2000)—is a prerequisite for moral condemnation and most legal punishment, and so being found blameworthy can have serious consequences, from social exclusion to imprisonment. But by what process do we determine that an action is worthy of blame?

This question has received a great deal of attention from philosophers (e.g., Austin, 1956; Feinberg, 1968; Hart, 1968; Hart \& Honore, 1959) and psychologists (Darley \& Zanna, 1982; Shultz \& Schleifer, 1983; Shultz, Schleifer, \& Altman, 1981; Shaver, 1985; Weiner, 1995), who have developed normative and descriptive accounts of how and why we blame. According to these theories, the prototypical blameworthy action is one where an agent causes harm to another, and does so intentionally (Shaver, 1985). While blame may also be ascribed to a lesser degree when either factor is present alone-people sometimes consider it blameworthy to cause harm even accidentally (Alicke, 1992), or to perform an act intended to harm another even if it fails (Cushman, 2008)— these theories of responsibility predict than an action will not be judged blameworthy if it involves neither harmful intent nor causal responsibility for a harmful outcome.

Yet there appear to be actions that are considered blameworthy even if they neither cause harm nor are performed with harmful intent. Consider, for example, the behavior of Greg Lippmann, a trader at Deutsche Bank who advised investors to bet on mortgage defaults. Lippmann's strategy was to purchase financial instruments that were linked to a pool of mortgages and that would became far more valuable if those mortgages went into default (i.e., if individual homeowners were unable to make the payments on their homes). Of course, Lippman's bet did not (and could not) cause the subprime mortgage crisis to occur. Neither did Lippman intend for his bet to cause a crisis. He merely sought to benefit from a tragic event that he knew to be beyond his control. From the perspective of the theories described earlier there is no basis on which to judge actions like Lippman's blameworthy, and yet the widespread public outcry against "short sellers" who engage in similar behavior suggests that people commonly do so. Why might this be the case?

We propose that one reason such actions may be deemed blameworthy is that individuals consider a person's desires as a target of moral evaluation, particularly when there is a desire for something harmful to occur. It is reasonable to infer that when someone is in a position to gain from an event, this produces an increased desire for it to occur. For instance, people who buy a lottery ticket likely desire that their winning numbers be drawn, and gamblers at a racetrack generally prefer that their horse win. Similarly, an investor who stands to benefit if homeowners are unable to pay their mortgages can be assumed to desire widespread defaults. We suggest that ordinary people consider it bad to desire widespread mortgage defaults (or, more generally, to desire that harm befall other people-what we refer to as a "wicked desire").

It is likely the case that people evaluate the character of a person who possesses such wicked 
desires more negatively-this would be consistent with a great deal of previous research demonstrating that desires and preferences influence judgments of an individual's underlying traits and dispositions (Funder, 2004). However, we suggest that information about an agent's desires may play a role not just in the assessment of an individual's underlying moral character, but in the moral evaluation of the actions themselves. Specifically, we suggest that people may consider it morally wrong for an agent to engage in any action that engenders a wicked desire. For instance, the reason Lippman may seem especially blameworthy for performing an action with no direct intention to harm nor that caused any harm is because the act of hedging against mortgages caused Lippman to root for the suffering of homeowners-a desire that likely did not exist before this action. An act may be deemed blameworthy, then, if it causes a person to adopt wicked desires.

The notion that desires play an important role in moral evaluation is not a new one. We know, for instance, that an action is judged more wrong and blameworthy when the agent desires to cause harm (Cushman, 2008; Pizarro, Uhlman, \& Salovey, 2003; Woolfolk, Doris \& Darley, 2006). However, "desire" in this sense is more centrally tied to the notion of intent, and as such plays a role that is perfectly consistent with standard models of moral blame, on which intent to cause harm is a critical feature of a blameworthy action. What is unusual about the case of betting on mortgage defaults is that the action (an investment) is not performed with the desire to cause harm, but merely with the hope of profiting from a harm that is likely to occur (for entirely independent reasons). Our prediction is that people may find it morally objectionable to engage in a behavior like betting on harm, not because the act causes harm, but rather because the actor is putting him or herself in a position to root for the harm to occur.

In the experiments that follow, we test this "wicked desires" account by examining people's moral judgments of harmless acts in which an individual benefits from the misfortune of others. In Study 1, we examine whether people do indeed judge such acts as blameworthy. In Studies 2-4, we test whether these judgments were explained by the wicked desires account outlined above, while also attempting to rule out alternative explanations.

\section{Study 1}

In Study 1 we tested whether people would judge harmless acts as blameworthy if these acts allowed an individual to benefit from another's misfortune. To do so, we created a scenario that conceptually paralleled the example described above (betting against the U.S. mortgage market). However, rather than using the emergence of a financial crisis as the harm from which an agent might benefit, we chose the occurrence of a natural disaster (i.e., an earthquake in a developing nation) because we assumed that, while participants might believe that financial bets could cause a financial crisis, they would not believe that financial bets could cause a natural disaster. Specifically, the scenario described a fund manager at a financial firm who invested in "catastrophe bonds," which were described as gaining in value either if an earthquake struck a certain developing country (harm condition) or if an earthquake did not strike the country (no harm condition). Thus, receiving a payoff in the harm condition was an instance of benefitting from a misfortune, whereas a payoff in the no harm condition was not.

In addition to asking participants about their judgments of blameworthiness of the fund manager's actions, we asked participants to make judgments about his overall character. This allowed us to test whether moral blame for benefitting from misfortune is simply a result of negative assessments of an individual's moral character.

Participants and Design

The study was administered online to 97 individuals recruited and paid via Amazon.com's Mechanical Turk web service (Paolacci, Chandler, \& Ipeirotis, 2010). ${ }^{1}$ All participants read a scenario describing Mr. Green, "a money manager at a large financial firm," who had decided to invest one of his funds in "catastrophe bonds." Participants randomly assigned to the harm condition $(\mathrm{n}=60)$ read that the bonds were "worth little unless a severe earthquake strikes a certain third world country in the next two years" and that "[s] ure enough, an earthquake strikes, causing great devastation, and the bonds become very valuable." Participants assigned to the no harm condition ( $\mathrm{n}=37$ ), read that the bonds gained value "as long as a certain third world country is 
NOT struck by an earthquake in the next two years," and that "[s]ure enough, there is no earthquake and the bonds become very valuable."

Participants then completed two items assessing the blameworthiness of Mr. Green's actions: "Do you think what Mr. Green did was morally wrong" from 1 (Not wrong at all) to 9 (Very wrong); and "To what extent should Mr. Green be morally blamed for his action" from 1 (Not blamed at all) to 9 (Blamed very much). Participants also completed two questions about Mr. Green's global character: "Do you think that Mr. Green is mainly a good person or a bad person?" from 1 (Mainly a bad person) to 9 (Mainly a good person); and "Do you think that Mr. Green has good moral standards?" from 1 (Not at all) to 9 (Completely). Finally, in order to assess whether the effect of the manipulation was moderated by how much experience participants' had with financial investments, we asked participants to indicate their investment experience on a scale from 1 (Very little) to 9 (A great deal). In order to minimize the length of the study, we did not collect demographic information.

\section{Results and Discussion}

As the item assessing investment experience did not moderate the results we will not discuss it further.

Because responses to the two action judgments $(r=.86, p<.0001)$ and the two character judgments $(r=.70, p<.0001)$ were highly correlated, we combined the first two items into a blameworthiness composite and the latter two items into a character composite. The two composites correlated significantly, $r=-.51, p<$ .0001 .

As predicted, participants viewed the money manager's actions as more blameworthy when he benefited from harm, as indicated by the blameworthiness composite scores across conditions: $M_{\text {barm }}=4.33, M_{n o \text { barm }}=2.35, t(95)=$ $4.15, p<.0001, d=.85$. Participants also saw the money manager's character as worse when he benefited from harm, as indicated by scores on the character composite across conditions: $M_{\text {barm }}=$ 4.84, $M_{n o}$ barm $=5.99, t(95)=3.55, p=.0006, d=$ .73. However, an ANCOVA on blameworthiness controlling for character judgments still showed a significant effect of condition, $F(1,94)=7.31, p=$ .008 .
As predicted, participants saw an action that benefited from harm as more blameworthy than an otherwise identical action that did not, even when controlling for negative assessments of the actor's character. These results provide the first evidence that people find benefiting from harm to be morally blameworthy, and that this is not simply a result of a greater willingness to blame individuals who are seen as having bad character. This was despite the fact that participants were unlikely to assume that the harm (an earthquake) could have been caused by the action (purchasing a bond).

\section{Study 2}

Study 1 demonstrated that individuals who benefit from harms that they neither cause nor intend to cause are nonetheless judged to be morally blameworthy. Study 2 tests plausible alternative explanations for this pattern of results. For instance, it may be that the negative affect resulting from reading about a harmful event (e.g., a natural disaster) might give rise to a greater overall willingness to ascribe blame. Just as people are more likely ascribe blame when they are feeling angry (even if the anger is elicited by an unrelated task; Goldberg, Lerner, \& Tetlock, 1999), participants in our study may have been more likely to make judgments of blame when reading about a misfortune, even when the individual being judged bore no causal responsibility for having brought about the event (we will call this the scapegoating account). A number of studies demonstrate "belief in a just world," according to which individuals are blamed for bad things that happen to them (Lerner, 1980). By analogy, participants in our study may have blamed bad individuals for bad things that happened to others. In the present experiment we attempted to rule out this alternative explanation.

Participants were asked to make judgments about a stock investor who took either a short position (i.e., betting that a stock would go decrease in value) or a long position (i.e., betting that a stock would increase in value). In addition, we manipulated whether the stock was described as actually increasing or decreasing in value. We hypothesized that as in Study 1 individuals would make more negative evaluations of the investor who stood to profit from the misfortune of others (by "shorting" the stock). Moreover, we included 
information about whether the stock increased or decreased in order to test two competing explanations for this effect. Specifically, we reasoned that if people view such actions as morally objectionable because they signal an underlying desire for harm to come about (the wicked desires account), participants should find the action objectionable regardless of the stock's actual performance. On the other hand, if reading about a negative outcome simply makes people more willing to blame (the scapegoating account), individuals would not find the short-selling objectionable if the negative outcome did not obtain.

\section{Participants and Design}

The study was administered online to 200 U.S. adults (114 female; ages 19-86; $M_{\text {age }}=35, S D_{\text {age }}=$ 12.27) who were recruited and paid via Amazon.com's Mechanical Turk web service (Paolacci, Chandler, \& Ipeirotis, 2010). All participants read about Mr. Brown, a wealthy investor who took a long or a short position on the stock of Widgetron, Inc. One group (the up condition) read that Widgetron's stock increased from $\$ 15$ to $\$ 25$; the other (the down condition) read that Widgetron's stock decreased from $\$ 15$ to $\$ 5$. Finally, participants were randomly assigned to read that Mr. Brown either made or lost "several million dollars" on his investment (whether Mr. Brown was described as making or losing money depended, of course, on whether he had correctly anticipated whether the stock's price would rise or fall). Participants then completed the same items used in Study 1: two items assessing the blameworthiness of Mr. Brown's actions, two items assessing his overall character, and one item assessing participants' investment experience (as in Study 1, this item did not moderate any results, so we do not discuss it further).

\section{Results and Discussion}

As in Study 1, we constructed a blameworthiness composite and a character composite by combining responses to the two action judgments $(r=.87, p$ $<.0001)$ and the two character judgments $(r=.60$, $p<.0001)$. The two composites correlated significantly, $r=-.30, p<.0001$.

Replicating the effect found in Study 1, a 2 (investment: short vs. long), x 2 (outcome: stock up vs. stock down) ANOVA on blameworthiness judgments showed that taking a short position was seen as more blameworthy than taking a long position, $M_{\text {sbort }}=3.68, M_{\text {long }}=2.55, F(1,196)=$ $12.79, p<.001$. Supporting the wicked desires account, the actual outcome (whether the stock actually increased or decreased in price) had no effect on blameworthiness judgments (nor did the interaction between outcome and investment; both $p$ s $>$.40). A planned contrast comparing the short/stock up with the short/stock down condition showed no significant difference, $F(1,196)=.19$, $n s$.

A parallel analysis examining character composite scores again showed a significant effect of investment (and replicated the results of Study 1): participants saw the investor's character as worse when he took a short position, $M_{\text {short }}=5.35$, $M_{\text {long }}=5.75, F(1,196)=4.14, p=.04$. However, as in Study 1, an ANCOVA on blameworthiness judgments controlling for character judgments still showed a significant effect of taking a short vs. a long position, $F(1,195)=9.59, p=.002$.

As in Study 1, participants judged actions that produced a desire for harm to be more blameworthy than otherwise identical actions that did not, and correspondingly judged individuals more harshly for the first type of action than the second. Also as in Study 1, blame for these actions did not depend on negative character judgments: An investor was blamed more for taking a short than a long position even controlling for assessments of his character.

Contrary to the scapegoating account (which would predict an indiscriminate increase in blame when a negative outcome obtains), these results demonstrate that the presence of actual harm (or benefit) is not necessary for this effect to occurparticipants judged even the attempt to benefit from harm as blameworthy. Rather, people seem to be willing to condemn mere attempts to benefit from harm, even when these attempts are unsuccessful.

\section{Study 3}

Studies 1 and 2 demonstrated that people find benefiting from harm-or even the attempt to do so- to be morally blameworthy. While Study 2 allowed us to rule out the scapegoating account to explain this effect, we have not yet shown direct evidence for the wicked desires account-that 
people see benefiting from harm to be blameworthy because it reflects a desire for a bad outcome to occur. We conducted Study 3 in order to provide more direct evidence for the wicked desires account, as well as to rule out another alternative explanation: that those who benefit from harm are seen as "magically" having caused a harmful outcome. While at first glance such a belief seems implausible among educated undergraduates, there is no lack of evidence that even well-educated undergraduates commonly harbor a variety of magical beliefs (Risen \& Gilovich, 2008; Rozin \& Nemeroff, 2002). Most relevant to the current research, Pronin and colleagues (2006) have shown that people sometimes believe that they have caused a desired outcome even when there is no way that they could have done so. For example, participants who performed a symbolic act of harm (a "voodoo hex") directed at a disliked confederate (whom the participants presumably wanted to harm) felt more responsible for the confederate's subsequent symptoms of physical illness than did those who targeted a neutral confederate. It may be that this is why participants in our studies judge these acts to be blameworthy-because they believe that desiring harm may in some way cause an increased chance that the harm will actually occur, and therefore those who desire harm bear causal responsibility for the outcome (we call this the magical thinking account).

In the current study we used the same scenario as in Study 1 (the catastrophe bond). Some participants read that the firm's profits were contingent on a good or bad outcome, whereas others read that the firm's profits were noncontingent on the outcome (i.e., the firm made a profit regardless of the outcome). We reasoned that in the contingent cases, participants would infer that the fund manager's behavior would produce a desire for harm because his profit would be contingent on harm. In the non-contingent cases, however, participants would be less likely to infer that the fund manager's behavior would produce a desire for harm because his profit would be identical whether or not the harm occurred. If the wicked desires account holds, individuals in this condition should be seen as less blameworthy for the same action (purchasing bonds that pay off in case of disaster).

As an additional method for distinguishing between these explanations we asked participants directly about their perceptions of the fund manager's desires. In addition, in order to test the possibility that participants held the belief that these desires might have a causal influence over the outcome, we also asked participants to report how much control the fund manager had over the outcome. Because participants' investment experience failed to moderate the results of the previous experiments, we did not assess it here. In order to minimize the length of the study, we also did not collect demographic information.

\section{Participants and Design}

The study was administered online to 116 U.S. adults, who were recruited and paid via Amazon.com's Mechanical Turk web service (Paolacci, Chandler, \& Ipeirotis, 2010). Participants were randomly assigned to one of four conditions in a 2 (investment: harm vs. no harm) x 2 (profit: contingent profit vs. non-contingent profit) between-subjects design. All participants read about Mr. Green, "a money manager at a large financial firm," who decides to invest one of his funds heavily in "catastrophe bonds." In the harm condition, the bonds were described as "worth little unless a severe hurricane strikes a certain third world country in the next two years, in which case they gain value." In the no harm condition, they were described as "worth little unless a certain third world country is NOT struck by a hurricane in the next two years, in which case they gain value."

In the contingent profit conditions, no additional information about Mr. Green's investment was provided. However, in the non-contingent profit conditions, Mr. Green was described as discovering that "many of his firm's investments in a certain third world country would lose a great deal of value [if a severe hurricane were to strike/unless a severe hurricane were to strike] in the next two years." Mr. Green purchases the catastrophe bonds in order to protect the firm against this possibility, so that "whether Mr. Green's firm makes money is not affected by whether a hurricane strikes." No outcome information (i.e., whether a hurricane struck) was given (see Appendix A for the full text of the scenarios).

Next, we assessed participants' perceptions of Mr. Green's desires and control over the outcome by asking them to indicate, on 9-point scales 
anchored by Totally disagree and Totally agree, how much they agreed that "Mr. Green was hoping a hurricane would strike the third world country;" "Mr. Green wanted a hurricane to strike the third world country;" "Somehow, Mr. Green affected what would happen to the third world country;" and "Mr. Green's behavior changed the likelihood that a hurricane would strike the third world country." These questions were presented in random order. Participants then completed the same four evaluation items used in the previous studies: two assessing the blameworthiness of $\mathrm{Mr}$. Green's actions and two assessing evaluations of his overall character.

\section{Results and Discussion}

We first examined whether our manipulation of motive had the expected effect on perceptions desires. Responses to the two "desire" items ("hoping a hurricane would strike" and "wanted a hurricane to strike") were highly correlated, $r(116)$ $=.93, p<.0001$, and were therefore combined into a single composite. A 2 (investment: harm vs. no harm) $\mathrm{x} 2$ (profit: contingent vs. non-contingent) ANOVA on this composite showed a significant interaction, $F(1,112)=84.65, p<.001$. Follow-up tests showed that the profit manipulation had the expected effect on perceptions of desires: In the contingent profit condition, Mr. Green was seen as much more desirous of a hurricane when he had bought bonds that paid off in the event of a hurricane strike: $M_{\text {barm }}=7.35, M_{n o \text { barm }}=1.20$, $t(112)=14.15, p<.0001$. In the non-contingent profit condition, Mr. Green's perceived desires were not judged differentially according to the kind of bonds he had bought, $M_{\text {harm }}=2.72, M_{n o}$ harm $=2.92$, $t(112)=.39, n s$ (see Figure 1).

We next examined participants' evaluations of the blameworthiness of Mr. Green's actions. As in previous experiments, the two blameworthiness items were highly correlated $(r=.87, p<.0001)$ and were combined into a composite.

A 2 (investment: harm vs. no harm) x 2 (profit: contingent vs. non-contingent) ANOVA on blameworthiness judgments showed a significant interaction, $F(1,112)=6.94, p=.01$ (see Figure 1). Follow-up tests (Tukey's HSD) showed that the interaction was due to greater condemnation of Mr. Green's behavior in the harm/ contingent profit condition $(M=4.78)$, which was significantly higher than in the other three conditions (all $p$ s <
.05). None of the other three conditions differed significantly from each other, $M_{\text {barm/non-contingent profit }}=$ 2.26, $M_{n o}$ barm/non-contingent profit $=2.45, M_{\text {no harm/ contingent profit }}=$ 2.76. Repeating these tests with a composite of the two character items $(\mathrm{r}=.84, p<.001)$ as a covariate showed that blameworthiness judgments remained significantly higher in the harm/contingent profit condition than in each of the other three conditions (all $p$ s $<.05$ ), which did not differ significantly from each other.

We next tested our causal model by examining whether perceptions of Mr. Green's desires mediated the interactive effects of investment and profit on blame. We first tested whether the desires composite predicted blame for his actions. It did, $\beta=.45, t(114)=5.39, p<.0001$. Next, we regressed action evaluations on the desires composite, investment condition, profit condition, and the investment $x$ profit interaction. Perceived desires continued to predict action evaluations, $\beta$ $=.36, t(111)=2.55, p=.01$, but the investment $\mathrm{x}$ profit interaction was no longer a significant predictor, $\beta=.04, t(111)=.36$, ns. A Sobel test confirmed that this drop was significant, indicating full mediation, $Z=2.46, p=.014$.

Finally, we examined whether perceptions of Mr. Green's control over the outcome (i.e., magical thinking) mediated evaluations of his actions. The two control items ("Somehow, Mr. Green affected what would happen to the third world country" and "Mr. Green's behavior changed the likelihood that a hurricane would strike the third world country") were only moderately correlated, $r=.30, p=.001$. Separately examining correlations between each of the control items and the blameworthiness evaluations showed that judgments of blame were marginally correlated with the "changed likelihood" item, $r(116)=.16, p=.09$, and significantly correlated with the "affected what would happen" item, $r(116)=.20, p=.03$ (no other correlations were significant, all $r$ < .12). However, neither control item was affected by investment, profit, or their interaction, all $t \mathrm{~s}<1.2$, all $p \mathrm{~s}>.25$. Thus, it does not appear that our participants regarded benefiting from harm as blameworthy because of a "magical" belief that desires can cause harmful outcomes.

The results of the current study buttress the results of Studies 1 and 2: Again, participants viewed attempts to benefit from harm as blameworthy, even when controlling for negative 
evaluations of the actor's character. However, the current results go beyond the previous findings by showing that these evaluations are mediated by perceived desire for a harmful outcome: When there was no reason to believe that Mr. Green wanted the harmful outcome to occur (because he would profit both if it took place and if it did not) his attempt to benefit from harm was not seen as blameworthy. Moreover, perceptions of $\mathrm{Mr}$. Green's desires for a harmful outcome mediated condemnation of his actions, lending further support for the "wicked desires" account.

Additionally, the results of the current study are inconsistent with the several proposed alternative explanations of the phenomenon. Because no outcome information was provided, the scapegoating account would predict no condemnation of mere attempts to benefit from harm. In addition, the two items included to assess whether participants thought that Mr. Green possessed control over a desired outcome did not differ across our experimental conditions, a result that is inconsistent with the magical thinking explanation.

\section{Study 4}

Studies 1-3 demonstrate that individuals are judged to be morally blameworthy when they position themselves to benefit from harm, which is mediated by perceptions of desires for a harmful outcome. In all three studies participants condemned attempts to benefit from harm even when controlling for their judgments of the actor's character, suggesting that negative evaluations of these acts do not simply reflect an indiscriminate willingness to condemn the actions of disliked individuals. In Study 4 we seek to provide further evidence of the independence of blame and character judgments. In particular we test whether people indiscriminately assign blame to any bet placed by an investor with a bad character, or instead selectively assign blame for the specific bets that lead individuals to adopt wicked desires.

In order to do so, we modified the catastrophe bond scenario used in previous studies. As before, half of participants read about a fund manager's decision to buy bonds that that become more valuable following a natural disaster (the bad manager), while half of participants read about the a fund manager's decision to buy bonds that become less valuable following a natural disaster (the good manager). (We predicted that the first manager would be judged bad and the second manager judged good based on the consistent results of Studies 1-3.) However, each scenario went on to describe those same managers later selling their bonds in order to have more cash on hand. Thus, each actor performs two actions: An initial investment in a catastrophe bond, and a subsequent divestment from that same bond.

If people are simply inclined to condemn any actions of immoral individuals, they should rate both actions (buying and selling the bonds) to be more morally bad when performed by the morally bad manager compared to when those actions are performed by the morally good manager. The initial investments would signal the moral character of the managers, and then information about moral character would subsequently influence the judgment of both the buying acts and the selling acts equally.

Our wicked desires account, however, predicts that buying bonds that appreciate when harm occurs will be judged a morally bad action, but subsequently selling those bonds will not be judged a morally bad action (even though the actor remains the same and character is therefore held constant). In other words, being a morally bad manager will not be sufficient to taint any transaction involving a catastrophe bond. Only those specific actions that adopt a wicked desire will be judged morally wrong.

\section{Participants and Design}

The study was administered online to 145 U.S. adults (87 female; ages 18-74; $M_{\text {age }}=35, S D_{\text {age }}=$ 12.36), who were recruited and paid via Amazon.com's Mechanical Turk web service (Paolacci, Chandler, \& Ipeirotis, 2010). Participants were randomly assigned to one of four conditions in a 2 (investment: harm vs. no harm) x 2 (action: buy vs. sell) between-subjects design. All participants read about Mr. Green, "a money manager at a large financial firm," who decides to invest one of his funds heavily in "catastrophe bonds." In the harm condition, the bonds were described as "worth little unless a severe earthquake strikes a certain third world country in the next two years, in which case they gain value." In the no harm condition, they were described as "worth little unless a certain third world country is NOT struck by an earthquake in 
the next two years, in which case they gain value." All participants then read that "the next day, Mr. Green's firm unexpectedly has to make a large cash payment to a major shareholder," and that "in order to come up with this cash, Mr. Green sells back the cat bonds he bought the day before." All participants then completed the two character evaluation items used in the previous studies.

Participants in the buy condition then saw a new page with the instruction to "consider Mr. Green's decision to BUY the catastrophe bonds" and were asked to evaluate this decision using the same action evaluation items used in the previous studies ("Buying the catastrophe bonds was morally wrong"; "Mr. Green should be morally blamed for buying the catastrophe bonds"). Participants in the sell condition made the same judgments, but regarding Mr. Green's decision to sell the bonds.

\section{Results and Discussion}

We first tested whether participants evaluated Mr. Green's character more negatively in the harm condition. The two character items were highly correlated, $r(145)=.87, p<.001$, and were therefore combined into a composite. As expected, in the harm condition evaluations of $\mathrm{Mr}$. Green's character were more negative $(M=4.92)$ than in the no harm condition $(M=6.39), t(143)=$ $5.05, p<.0001$. Thus, our manipulation successfully affected evaluations of Mr. Green's character.

We next examined evaluations of Mr. Green's actions. The two action evaluation items were highly correlated, $r(145)=.79, p<.001$, and were combined into a composite measure of blame. Inspecting these composite scores revealed substantial positive skew (skewness $=.755$; kurtosis $=-1.03$ ) so non-parametric tests were used. A Kruskal-Wallis non-parametric ANOVA showed that blame differed significantly by condition, $\chi^{2}(3)=8.36, p=.04$. Follow up tests (Mann-Whitney $U$ ) showed that in the harm/buy condition-in which Mr. Green bought bonds that paid off in case of disaster-blame was significantly higher $(M=4.58, S D=2.57)$ than in each of the other three conditions $\left(M_{\text {harm } / \text { sell }}=3.35\right.$, $S D=2.32 ; M_{n o}$ harm/buy $=3.26, S D=2.37 ; M_{n o}$ harm/sell $=$ $3.08, S D=1.85)$, all $p$ s $<.03$. None of the other conditions differed significantly from each other, all $p$ s $>.60$ (see Figure 2). ${ }^{2}$ Thus, these results support the wicked desires account, which predicts that only actions that position one to benefit from harm should elicit increased blame, over the indiscriminate condemnation account, which predicts that an agent who has demonstrated bad character by buying bonds that appreciate after disasters should also be blamed for subsequently selling them.

The results of this study buttress the results of Studies 1-3: In those studies, statistically controlling for character judgments did not eliminate blame for attempts to benefit from harm. In the current study, we experimentally demonstrate a dissociation between judgments of blame and evaluations of character. Character evaluations were more negative when actors had attempted to benefit from harm, but only actions that positioned them to do so were seen as blameworthy. These results show that attempts to benefit from harm are seen as morally blameworthy independent of people's negative evaluations of the beneficiary's moral character.

\section{General Discussion}

Across four experiments we provided evidence that people judge an individual as blameworthy if he positions himself to benefit from harm-even if he has no control over whether the harm occurs. Moreover, we found that even mere attempts to benefit from harm were seen as blameworthy, both when they were unsuccessful (Study 2) and when no outcome information was available (Study 3). As predicted by our wicked desires account, moral disapproval of these acts was mediated by the assumptions about the individual's underlying desires: Individuals benefitting from harm were seen as possessing a desire for the harm to occur, which in turn led to moral condemnation. However, this effect was eliminated if the benefit from harm functioned to offset another corresponding cost, such that the individual had no overall reason to prefer harm to non-harm (Study 3). By changing participants' perceptions of the desires likely to result from the individual's behavior, this information eliminated blame for benefiting from harm. Blame for benefiting from harm was not merely the result of negative evaluations of the beneficiary's character: In Studies 1-3, statistically controlling for negative evaluations of the 
individual's character did not eliminate blame for benefiting from harm. In Study 4, we found that character evaluations of individuals who had attempted to benefit from harm were more negative, but only actions that actually positioned them to do so were seen as blameworthy.

These results are problematic for psychological theories of blame and responsibility which emphasize the presence of causal responsibility for harm and the intention to cause harm as necessary for the attribution of moral blame (e.g. Fincham \& Shultz, 1981; Piaget, 1932; Shaver, 1985; Weiner, 1995). We have suggested an alternative account - that participants assign moral blame even in the absence of causality and intentionality when the act in question requires the actor to adopt a wicked desire. In the current experiments, individuals who benefitted from harm chose to "root" for a bad outcome, and these desires were sufficient to trigger judgments of blame and bad character even when it was obvious that the individual had no causal control over the harm that occurred. While the current studies do not contradict the weight of evidence demonstrating that causal responsibility for harm and intent to harm are sufficient to trigger moral condemnation, it provides evidence that they are not always necessary-adopting wicked desires would also appear sufficient.

These findings appear more consistent with the theoretical approach of Tetlock and colleagues, who have proposed a sacred value protection model of moral judgment (SVPM; Tetlock, 2003; Tetlock et al., 2000), although even this approach cannot fully account for the current findings. The SVPM posits that people deem some values (e.g., preserving human life) to be "sacred," and react with moral outrage when these values are "contaminated" by non-sacred concerns such as financial profit. For instance, in the scenarios we describe, it may be that merely contemplating a harmful outcome (especially in the context of financial decisions) might give rise to judgments of blameworthiness. Yet the SVPM cannot explain several core findings of our studies. For one, the contemplation of a harmful event alone does not appear sufficient to explain the difference in judgments for an actor who placed a bet for or against that event-both parties would be equally "guilty" of considering the event. More importantly, the SVPM would not predict that manipulating the perception of an actor's desires would affect whether speculating on disasters was deemed blameworthy. Along the same lines, it would not predict differing moral evaluations of buying vs. selling financial instruments that allow one to profit from a natural disaster. All of these behaviors can, in an important way, be seen as contaminating the "sacred" domain of human life with financial speculation. Finally, the SVPM would have difficulty explaining negative moral evaluations when the sacred domain does not enter the picture (such as the study in which an agent is judged to be blameworthy for "shorting" a stock to make a profit), since monetary profit or loss is not held as a sacred moral value. Thus, while our data do not contradict the SVPM, it cannot explain the core pattern of results that motivates the wicked desires account.

\section{Implications for a character-based account of moral judgment}

Having demonstrated that moral assessments do track wicked desires, we now turn to a more fundamental question: Why? Our results are consistent with recent suggestions that moral evaluations of acts often depend on what these acts imply about the actor's character (Pizarro \& Tanenbaum, in press; Pizarro \& Helzer, in press). Put simply, one way that people appear answer the question "was that action wrong?" is to ask the question, "could only a bad person have done it?" Consider several examples. One recent study shows that people tend to judge a difficult moral decision (e.g., whether to deny an expensive organ transplant to a needy patient) more harshly if it is made quickly and without qualms, as compared to slowly and with much deliberation (Critcher, Inbar, \& Pizarro, 2011). People seem to reason that only a bad person could make such a decision without hesitation or conflict, and this leads them to judge the action blameworthy. Another recent study showed that people consider it worse to fire a small fraction of employees of one race than to fire a full complement of employees comprising several races-even though the latter action harms every person the former action does and many more to boot (Uhlmann, Tannenbaum, \& Diermier, in press). People seem to reason that only a bad person would single out and fire employees of one race, and this leads them to judge the (quantitatively) less harmful action to be more blameworthy. Similarly, in the present study 
people may reason, "only a bad person could be comfortable adopting the desire harm to others," and therefore conclude that betting on harm is wrong.

This model may generalize to a host of other behaviors. For example, imagine someone who sticks pins into a voodoo doll representing a rival (without any belief, of course, that this will actually work), or someone who mutilates pictures of his or her ex-boyfriend or ex-girlfriend. We suspect that people would conclude that only a bad person could perform these actions because of the desires that they require the agent to adopt. Thus, the actions themselves might be judged morally wrong and blameworthy despite the full knowledge that they could not possibly cause harm. Similarly, people's willingness to condemn symbolic offenses-such as cleaning one's toilet with the national flag (Haidt, Koller, \& Dias, 1993) — may be due at least in part to the negative character inferences that these actions are taken to support.

While the above-mentioned examples (like many hypothetical stimuli employed in the study of moral judgment) are both uncommon and somewhat artificial, financial instruments allowing one to benefit from harm are common and widely accepted among financial professionals. For example, "life settlement-backed securities"-or, more bluntly, "death bonds"-allow people holding life insurance to sell their policies to investors, who pay the premiums and then collect the payout when the policy-holder dies. Major investment banks have recently discovered that these policies can be pooled, converted into bonds, and sold to institutional investors as pensions and mutual funds (Goldstein, 2007). We have suggested one reason that people find these kinds of financial instruments objectionable, and we believe that their designers and purchasers may do well to keep the widespread aversion to benefiting from harm in mind.

Although further research is required before we fully understand how inferences about character shape the moral evaluation of actions, the first step may be to adjust descriptive theories of moral judgment to account for the growing evidence that people judge acts not only the basis of local intentions and outcomes, but also on the basis of how those actions shape an individuals' desires, and what they imply about the actor's moral character. We believe that this approach not only explains results that might otherwise be regarded as performance errors or anomalies, but also provides a fuller and more accurate picture of people's real-world moral judgments.

\section{Footnotes}

1. In order to minimize length, we did not collect demographic information in Studies 1 and 3, although we did use Amazon.com's respondent selection tools to restrict our studies to U.S. adults. When we did collect demographics in Study 2, we found that gender and age $(57 \%$ female; $M$ age $=35$ ) were remarkably close to those reported by Paolacci, Chandler, \& Ipeirotis (2010) for a sample of 1,000 Mechanical Turk workers collected in early $2010(64.85 \%$ female, $M$ age $=36$ ). As Paolacci, Chandler, \& Ipeirotis point out, although this population is younger and (obviously) more female than the U.S. population as a whole, it is nevertheless a good deal more representative of the population than are the undergraduate subject pools often used in psychological research.

2. Using a conventional (i.e., parametric) $2 \times 2$ ANOVA, the omnibus interaction test was not significant, $F(1,141)=1.85, p=.18$. This was true even after the data were log-transformed, $F(1$, $141)=2.63, p=.11$. However, as Bobko (1986) shows, omnibus interaction tests in ANOVA lack power when - as in the current study - an ordinal interaction is expected (that is, when one cell is expected to differ from all others). Following Bobko's two-step procedure for testing ordinal interactions showed that blame in the harm/sell, no harm/sell, and no harm/buy conditions did not differ, $F(2,105)=.14, p=.87$; and that blame was higher in the harm/buy condition than in the other three conditions, planned contrast $F(1,141)=$ $9.42, p=.003$.

\section{References}

Alicke, M. D. (1992). Culpable causation. Journal of Personality and Social Psychology, 63, 368-378.

Alicke, M. D. (2000). Culpable control and the psychology of blame. Psychological Bulletin, 126, 556-574.

Austin, J. L. (1956). A plea for excuses. Proceedings of the Aristotelian Society. 57, 1-30. 
Baron, J., \& Ritov, I. (2004). Omission bias, individual differences, and normality. Organizational Behavior and Human Decision Processes, 94, 74-85.

Bobko, P. (1986). A solution to some dilemmas when testing hypotheses about ordinal interactions. Journal of Applied Psychology, 71, 323-326.

Brody, D. C., Acker, J. R., \& Logan, W. A. (2000). Criminal Law. New York: Aspen Publishers.

Critcher, C., \& Inbar, Y., \& Pizarro, D. A. (2011). How quick decisions illuminate moral character. Manuscript submitted for publication.

Cushman, F.A. (2008). Crime and punishment: Distinguishing the roles of causal and intentional analyses in moral judgment. Cognition, 108, 353-380.

Darley, J. M., \& Shultz, T. R. (1990). Moral rules their content and acquisition. Annual Review of Psychology, 41, 525-556.

Darley, J. M., Zanna, M. P. (1982). Making moral judgments. American Scientist, 70, 515-521.

Feinberg, J. (1968). Action and responsibility. In A. R. White (Ed.), The Philosophy of Action. (pp. 95-119). Oxford: Oxford University Press

Fincham, F. D., \& Shultz, T. R. (1981). Intervening causation and the mitigation of responsibility for harm. British Journal of Social and Clinical Psychology, 20, 113-120.

Fincham, F. D., \& Shultz, T. R. (1981). Intervening causation and the mitigation of responsibility for harm. British Journal of Social Psychology, 20, 113-120.

Funder, D. C. (2004). The personality puzzle (3rd ed.). New York: W. W. Norton.

Goldberg, J. H., Lerner, J. S., \& Tetlock, P. E. (1999). Rage and reason: The psychology of the intuitive prosecutor. European Journal of Social Psychology, 29, 781-795.

Goldstein, M. (2007, July 30). Profiting from mortality. BusinessWeek, $x x, 44-51$

Haidt, J., Koller, S., \& Dias, M. (1993). Affect, culture, and morality, or is it wrong to eat your dog? Journal of Personality and Social Psychology, 65, 613-628

Hart, H. L. A. (1968). Punishment and Responsibility: Essays in the Philosopby of Law. Oxford: Clarendon Press.

Hart, H. L. A., \& Honore, T. (1959). Causation in the law. Oxford: Clarendon Press.
Heider, F. (1958). The psychology of interpersonal relations. New York: Wiley.

Imamoglu, E. O. (1975). Children's awareness and usage of intention cues. Child Development, 46, 39-45.

Lerner, M. J. (1980). The belief in a just world: A fundamental delusion. New York: Plenum Press.

Morgenson, G., \& Story, L. (2009, December 24). Banks bundled bad debt, bet against it and won. The New York Times, p. A1.

Paolacci, G., Chandler, J., Ipeirotis, P. G. (2010). Running experiments using Amazon Mechanical Turk. Judgment and Decision Making, 5, 411-419.

Piaget, J. (1965/1932). The moral judgment of the child. New York: Free Press.

Pizarro, D. A., Uhlmann, E., \& Bloom, P. (2003). Causal deviance and the attribution of moral responsibility. Journal of Experimental Social Psychology, 39, 653-660.

Pizarro, D. A., Uhlmann, E., \& Salovey, P. (2003). Asymmetry in judgments of moral blame and praise: The role of perceived metadesires. Psychological Science, 14, 267-272.

Pizarro, D.A. \& Helzer, E. (in press). Freedom of the will and stubborn moralism. In R.F.

Baumeister, A.R. Mele, and K. D. Vohs (Eds.) Free will and consciousness: How might they work? Oxford University Press.

Pizarro, D.A. \& Tannenbaum, D. (in press). Bringing character back: how the motivation to evaluate character influences judgments of moral blame. In M. Mikulincer \& P. Shaver (Eds.), The Social psychology of morality: Exploring the causes of good and evil. APA Press.

Pronin, E., Wegner, D. M., McCarthy, K., \& Rodriguez, S. (2006). Everyday magical powers: The role of apparent mental causation in the overestimation of personal influence. Journal of Personality and Social Psychology, 91, 218-231.

Risen, J. L., \& Gilovich, T. (2008). Why people are reluctant to tempt fate. Journal of Personality and Social Psychology, 95, 293-307

Rozin, P., \& Nemeroff, C. (2002). Sympathetic magical thinking: The contagion and similarity "heuristics." In T. Gilovich, D. Griffin, \& D. Kahneman (Eds.), Heuristics and biases: The psychology of intuitive judgment. (pp. 201-216). Cambridge: Cambridge University Press.

Shaver, K. G. (1985). The attribution of blame: Causality, responsibility, and blameworthiness. New 
York: Springer-Verlag.

Shultz, T. R., \& Schleifer, M. (1983). Towards a refinement of attribution concepts. In J. Jaspars, F. D. Fincham, \& M. Hewstone (Eds.), Attribution theory and research: Conceptual, developmental, and social dimensions (pp. 37-62). New York: Academic Press.

Shultz, T. R., Schleifer, M., \& Altman, I. (1981). Judgments of causation, responsibility, and punishment in cases of harm-doing. Canadian Journal of Behavioral Science, 13, 238-253.

Tetlock, P. E. (2003). Thinking about the unthinkable: Coping with secular encroachments on sacred values. Trends in Cognitive Science, 7, 320-324.

Tetlock, P. E., Kristel, O., Elson, B., Green, M., \& Lerner, J. (2000). The psychology of the unthinkable: Taboo trade-offs, forbidden base rates, and heretical counterfactuals. Journal of Personality and Social Psychology, 78, 853-870.

Weiner, B. (1995). Judgments of responsibility: A foundation for a theory of social conduct. New York: Guilford Press.

Woolfolk, R. L, Doris, J. M., and Darley, J. M. (2006). Identification, situational constraint, and social cognition: Studies in the attribution of moral responsibility. Cognition, 100, 283301.

Young, L., Cushman, F., Hauser, M., Saxe, R. (2007). The neural basis of the interaction between theory of mind and moral judgment. PNAS, 104, 8235-8240.

Yuill, N., \& Perner, J. (1988). Intentionality and knowledge in childrens' judgments of actors responsibility and recipients emotional reaction. Developmental Psychology, 24, 358-365.

Zelazo, P. D., Helwig, C. C., \& Lau, A. (1996). Intention, act, and outcome in behavioral prediction and moral judgment. Child Development, 67, 2478-2492. 

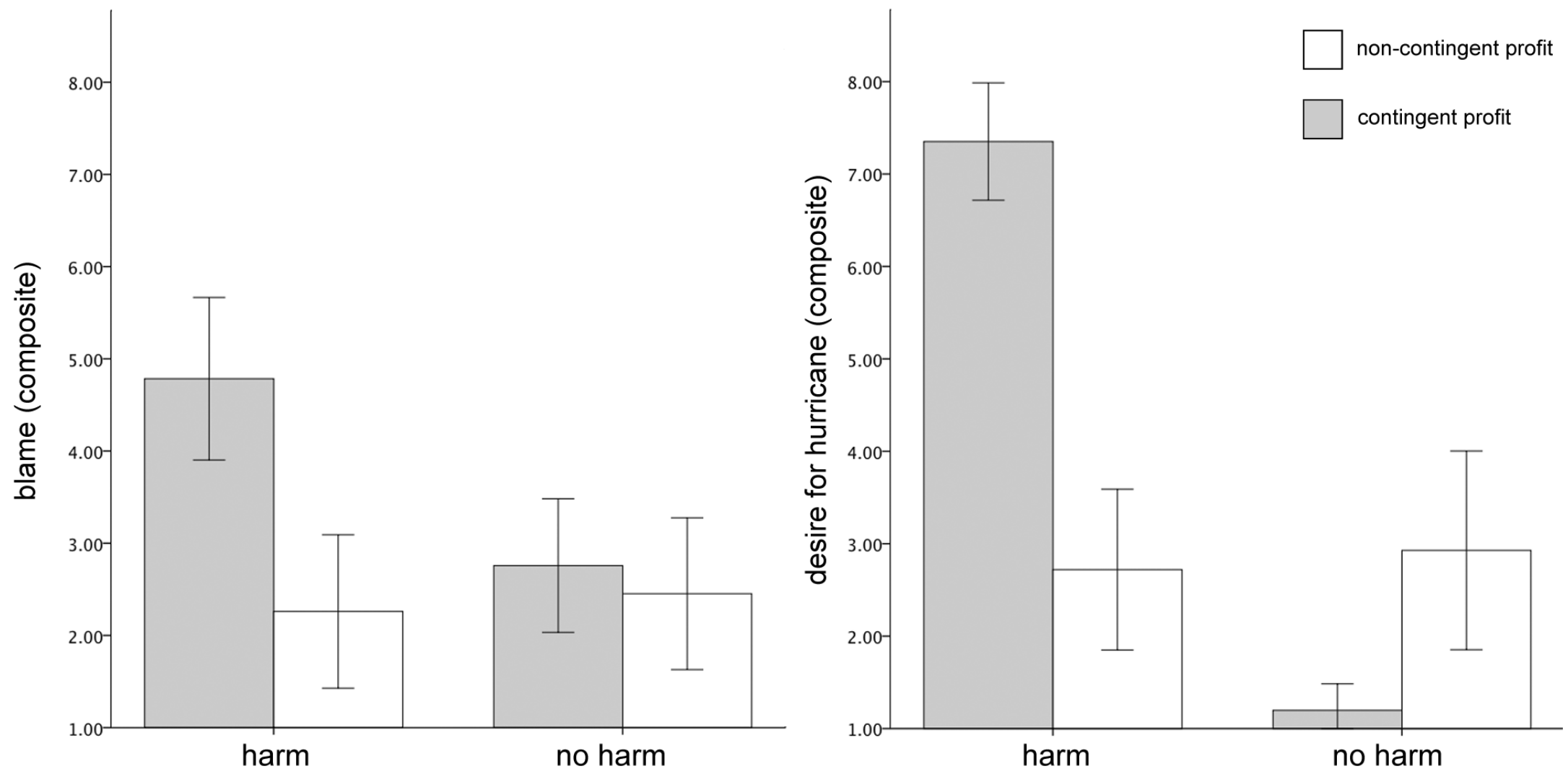

Figure 1. Blameworthiness of Mr. Green's behavior (left panel) and perceived desires (right panel) by investment and profit condition. Higher values reflect greater blame and greater perceived desires for the harmful event. Error bars are 95\% confidence intervals. 
BENEFITING FROM MISFORTUNE 14
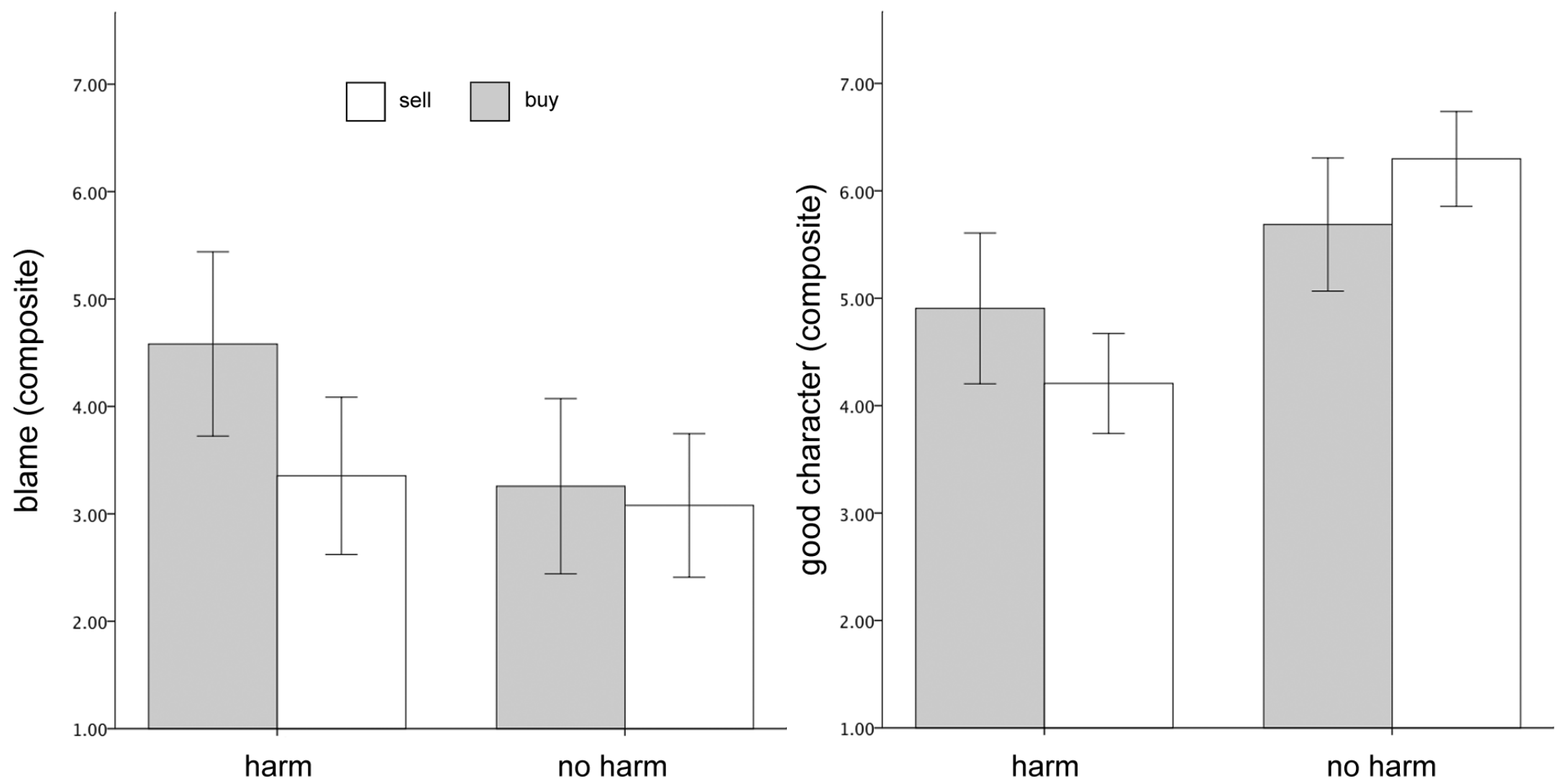

Figure 2. Blameworthiness of Mr. Green's behavior (left panel) and evaluations of his character (right panel) by investment and action condition. Higher bars in the left panel reflect greater blame; higher bars in the right panel reflect more positive character judgments. Error bars are 95\% confidence intervals. 
BENEFITING FROM HARM 15

\section{Appendix A}

Harm/ contingent profit:

Mr. Green is a money manager at a large financial firm. He decides to invest one of his funds heavily in catastrophe bonds, or "cat bonds." These bonds are worth little unless a severe hurricane strikes a certain third world country in the next two years, in which case they gain value. So Mr. Green's firm makes money only if a hurricane strikes the third world country.

No barm/ contingent profit:

Mr. Green is a money manager at a large financial firm. He decides to invest one of his funds heavily in catastrophe bonds, or "cat bonds." These bonds gain value as long as a certain third world country is NOT struck by a hurricane in the next two years. So Mr. Green's firm makes money only if a hurricane does NOT strike the third world country.

\section{Harm/non-contingent profit:}

Mr. Green is a money manager at a large financial firm. He discovers that many of his firm's investments in a certain third world country would lose a great deal of value if a severe hurricane were to strike in the next two years. In order to protect the firm against this, he decides to invest one of his funds heavily in catastrophe bonds, or "cat bonds." These bonds are worth little unless a severe hurricane strikes the third world country in the next two years, in which case they gain value. So whether Mr. Green's firm makes money is not affected by whether a hurricane strikes the third world country.

No barm/non-contingent profit

Mr. Green is a money manager at a large financial firm. He discovers that many of his firm's investments in a certain third world country will lose a great deal of value UNLESS a severe hurricane were to strike in the next two years. In order to protect the firm against this, he decides to invest one of his funds heavily in catastrophe bonds, or "cat bonds." These bonds gain value as long as the third world country is NOT struck by a hurricane in the next two years. So whether Mr. Green's firm makes money is not affected by whether a hurricane strikes the third world country. 